\title{
Supporting Information \\ Room Temperature Migration of Ag Atoms to Cover Pd Islands on Ag(111)
}

Buddhika S. A. Gedara, Mark Muir, Arephin Islam, Dairong Liu, and Michael Trenary*

Department of Chemistry, University of Illinois at Chicago, 845 West Taylor Street, Chicago, Illinois 60607

*mtrenary@uic.edu

S1. Clean Ag(111) surface
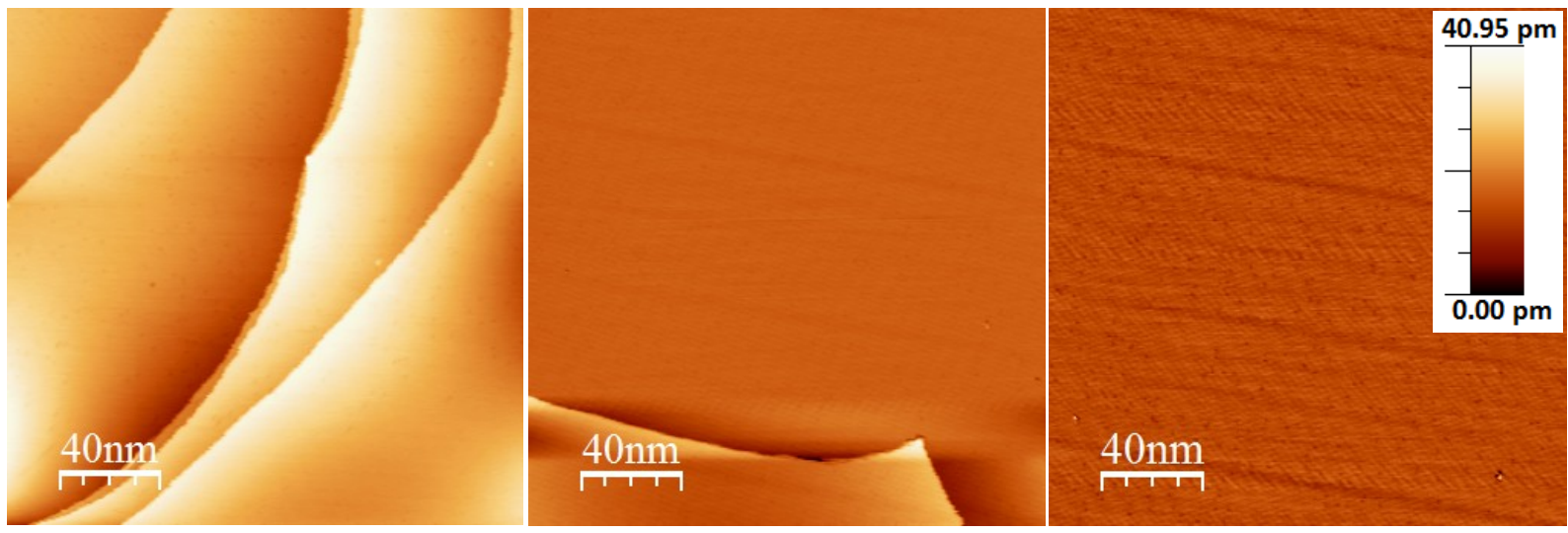

Figure S1. Clean $\operatorname{Ag}(111)$ surface with monolayer step edge and wide terraces. Images were acquired at $\mathrm{I}=0.2 \mathrm{nA}, \mathrm{V}=1.0 \mathrm{~V}$. 


\section{S2. Images 48 hours after Pd deposition}
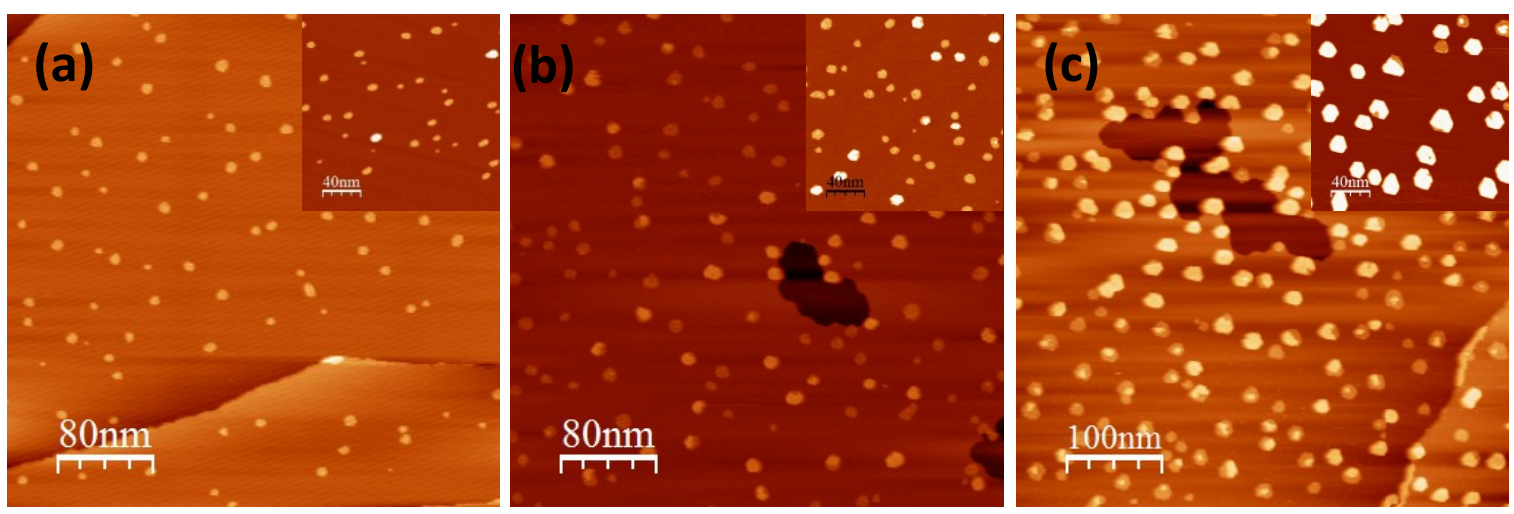

Figure S2. STM topographic images of $\mathrm{Pd} / \mathrm{Ag}(111) 48$ hours after Pd deposition. (a) 0.028 ML Pd, $400 \times 400 \mathrm{~nm}^{2}$ with a $200 \times 200 \mathrm{~nm}^{2}$ inset. (b) $0.064 \mathrm{ML} \mathrm{Pd}, 400 \times 400 \mathrm{~nm}^{2}$ with a $200 \times 200 \mathrm{~nm}^{2}$ inset. (c) $0.150 \mathrm{ML}$ Pd $500 \times 500 \mathrm{~nm}^{2}$, with a $130 \times 130 \mathrm{~nm}^{2}$ inset. Images were recorded at $0.20 \mathrm{nA}, 2.0 \mathrm{~V}-1.0 \mathrm{~V}$.

\section{S3. Line profiles at the step edge}
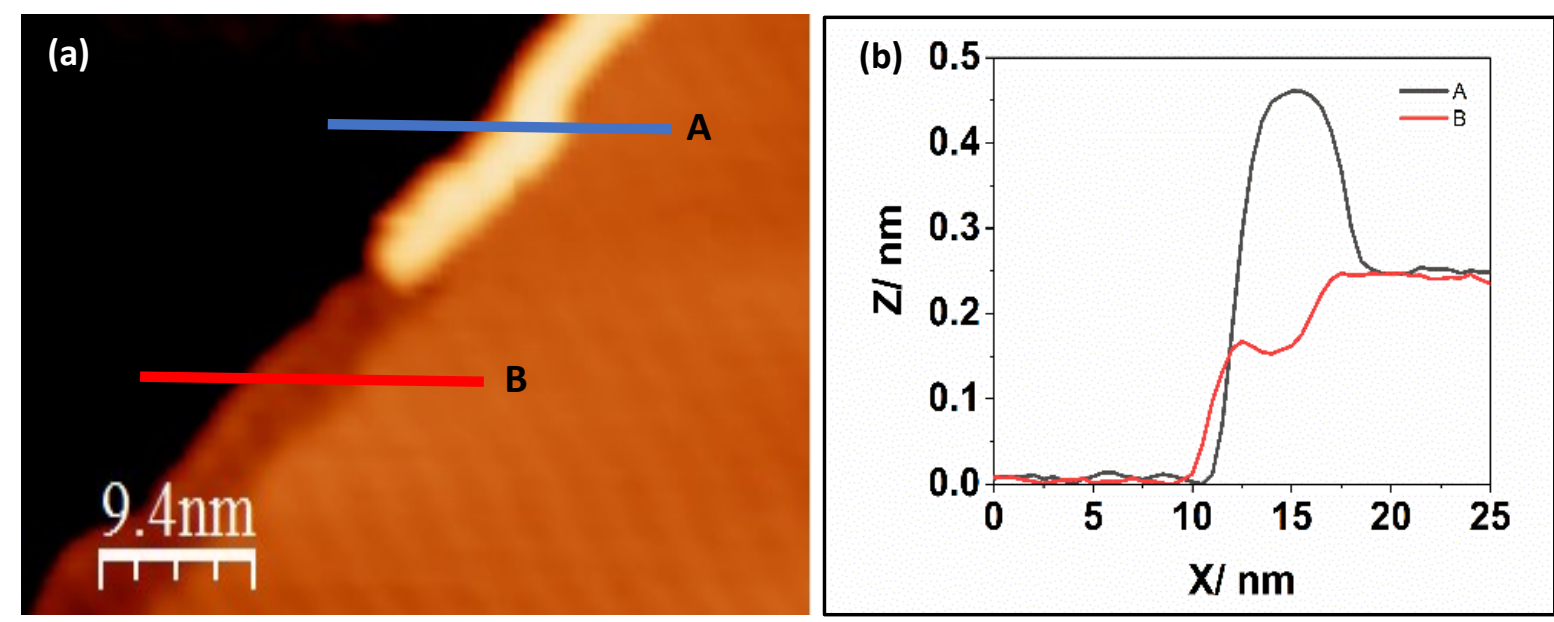

Figure S3. (a) STM topographic image in the vicinity of a step edge for $0.150 \mathrm{ML} \mathrm{Pd} / \mathrm{Ag}(111)$. (b) Height profile along line A and B in (a). Maximum height along line A is $0.45 \mathrm{~nm}$, which is similar to the height of the double layer islands on the terraces indicating that the Pd seam is encapsulated by Ag atoms. Height near step edge along line B is $0.15 \mathrm{~nm}$. This is the height of $\mathrm{Pd}$ islands on the Ag terraces. 

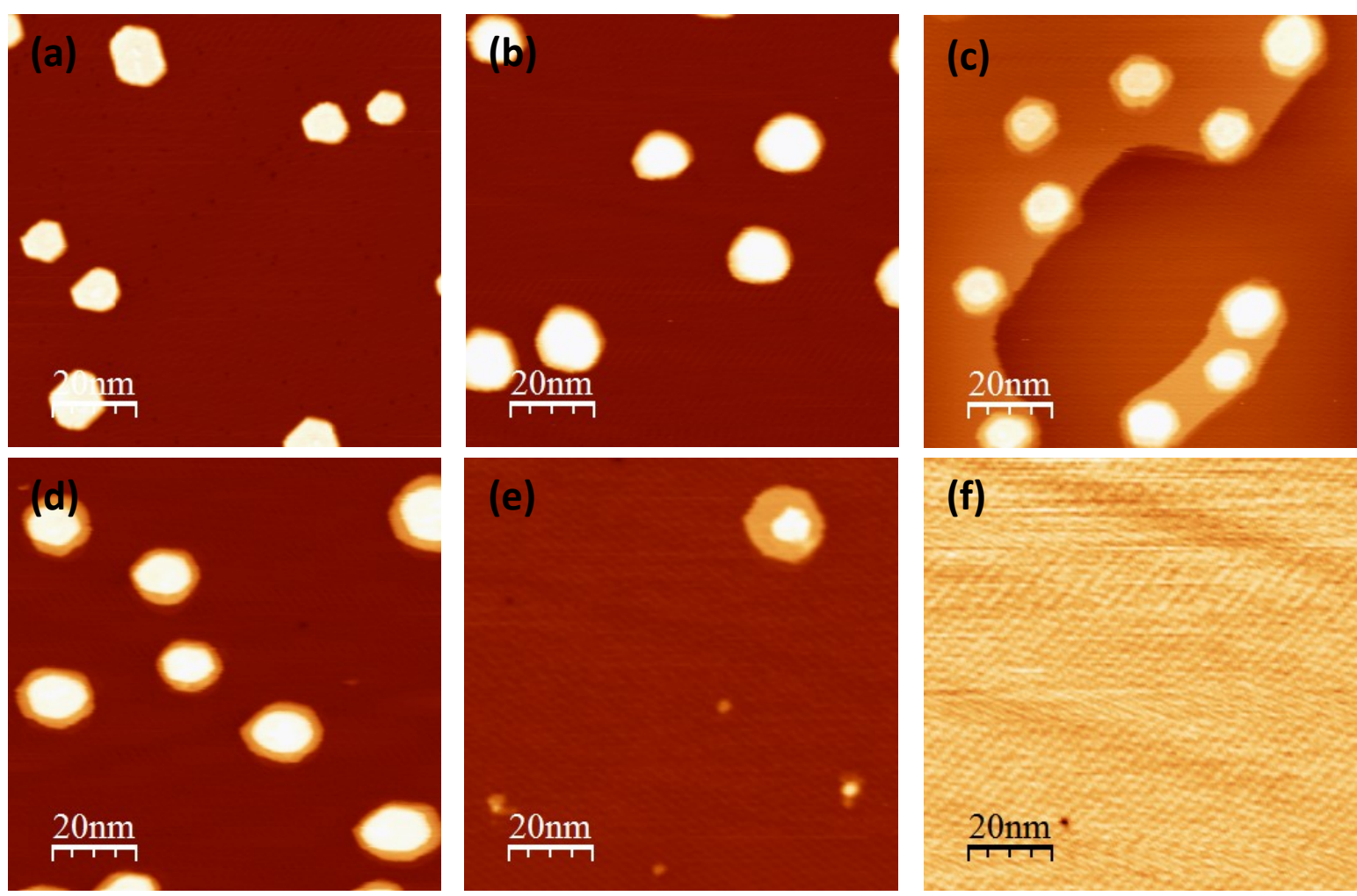

Figure S4. STM topographic images of $0.064 \mathrm{ML}$ of $\mathrm{Pd}$ on $\mathrm{Ag}(111)$ annealed to (a) $340 \mathrm{~K}$ (b) $390 \mathrm{~K}$ (c) $420 \mathrm{~K}$ (d) $440 \mathrm{~K}$ (e) $450 \mathrm{~K}$ and (f) $470 \mathrm{~K}$. Images were acquired at $0.20 \mathrm{nA}, 1.0 \mathrm{~V}$. Annealing here and in the other figures consisted of heating to the target temperature and holding it there for $30 \mathrm{~s}$, before cooling back to room temperature where the images were acquired. The annealing process generally took about 10 minutes. 

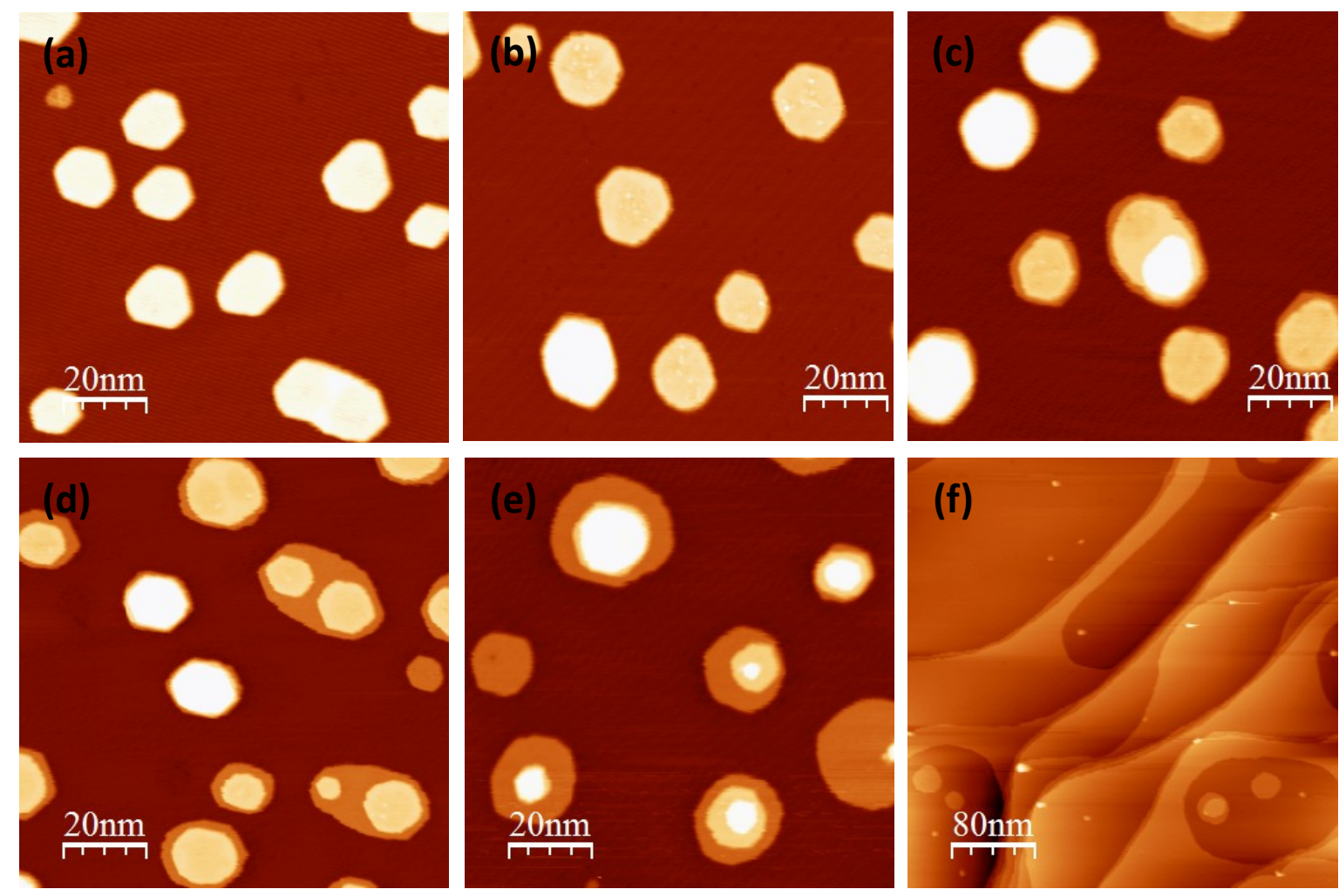

Figure S5. STM topographic images of 0.150 ML of Pd on $\mathrm{Ag}(111)$ annealed to (a) $340 \mathrm{~K}$, (b) $390 \mathrm{~K}$, (c) $420 \mathrm{~K}$, (d) $440 \mathrm{~K}$, (e) $450 \mathrm{~K}$, and (f) $470 \mathrm{~K}$. Imaging conditions were $0.20 \mathrm{nA}, 1.0$ $\mathrm{V}$.
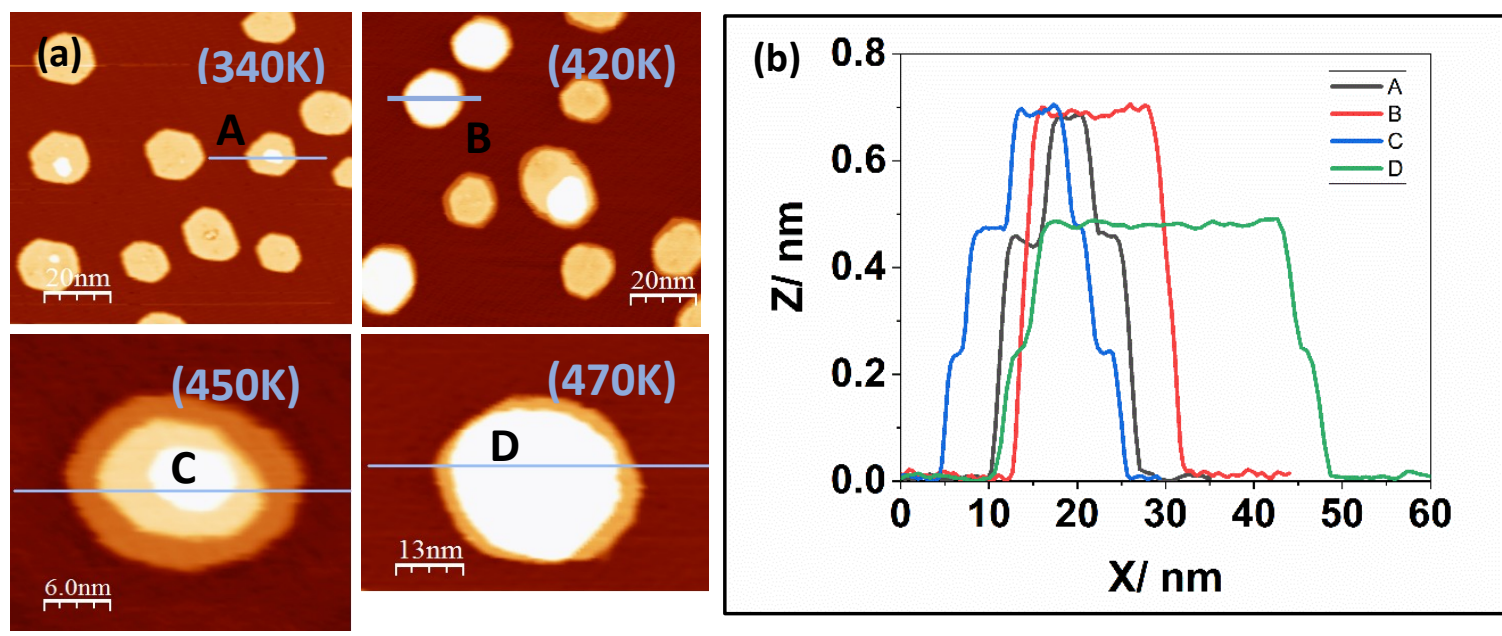

Figure S6. (a) STM topographic images of $0.150 \mathrm{ML}$ of Pd after annealing to the indicated temperatures. Images were acquired at $0.20 \mathrm{nA}, 1.2 \mathrm{~V}$. (b) Height profiles along A, B, C and D. Maximum height of $\mathrm{A}, \mathrm{B}$, and $\mathrm{C}$ is $0.680 \pm 0.005 \mathrm{~nm}$ indicating that the composition of those islands is $\mathrm{Ag} / \mathrm{Ag} / \mathrm{Pd} / \mathrm{Ag}(111)$. Maximum height of $\mathrm{D}$ is $0.470 \pm 0.005 \mathrm{~nm}$ indicating that its composition is $\mathrm{Ag} / \mathrm{Ag} / \mathrm{Ag}(111)$. 

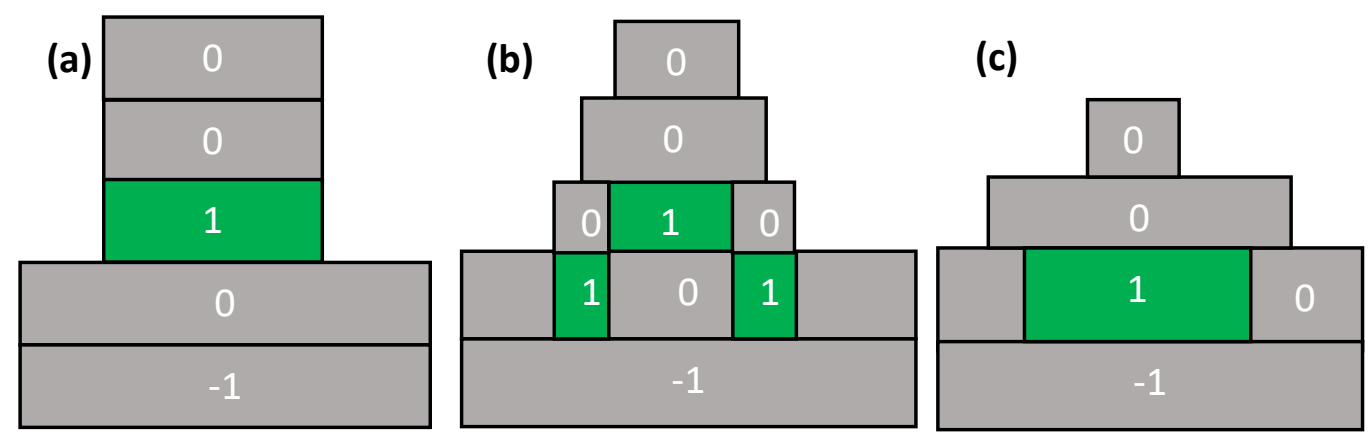

Figure S7. Sketches of the composition of the islands. (a) $\mathrm{Ag} / \mathrm{Ag} / \mathrm{Pd} / \mathrm{Ag}(111)$ (island B shown in Figure S6). (b) Island C shown in Figure S6. (c) Island D shown in Figure S6. $0=$ Surface $\mathrm{Ag}$ atoms; $1=\mathrm{Pd}$ atoms; and $-1=$ Subsurface Ag atoms.
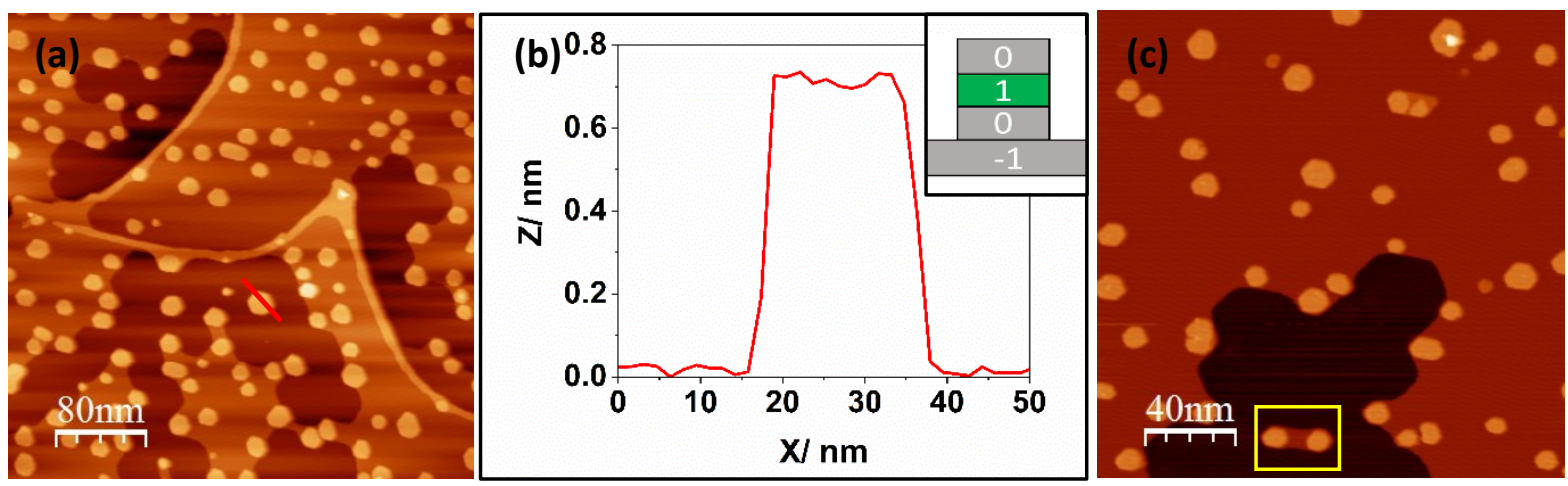

Figure S8. (a) $0.150 \mathrm{ML}$ of $\mathrm{Pd} / \mathrm{Ag}(111)$ annealed at $340 \mathrm{~K}$. When $\mathrm{Ag}$ vacancy pits grow, bilayer Pd islands appear isolated in the vacancy area. (b) Height profile corresponding to the red line through the island in (a). This height is the same as the height of a $\mathrm{Ag} / \mathrm{Ag} / \mathrm{Pd} / \mathrm{Ag}(111)$ island, but the composition is $\mathrm{Ag} / \mathrm{Pd} / \mathrm{Ag} / \mathrm{Ag}(111)$ as shown in the inset. (c) Isolated islands in marked area for $0.064 \mathrm{ML}$ of Pd after annealing to $340 \mathrm{~K}$.

\section{S5. Stacking fault tetrahedra (SFT)-like features on the Pd island}
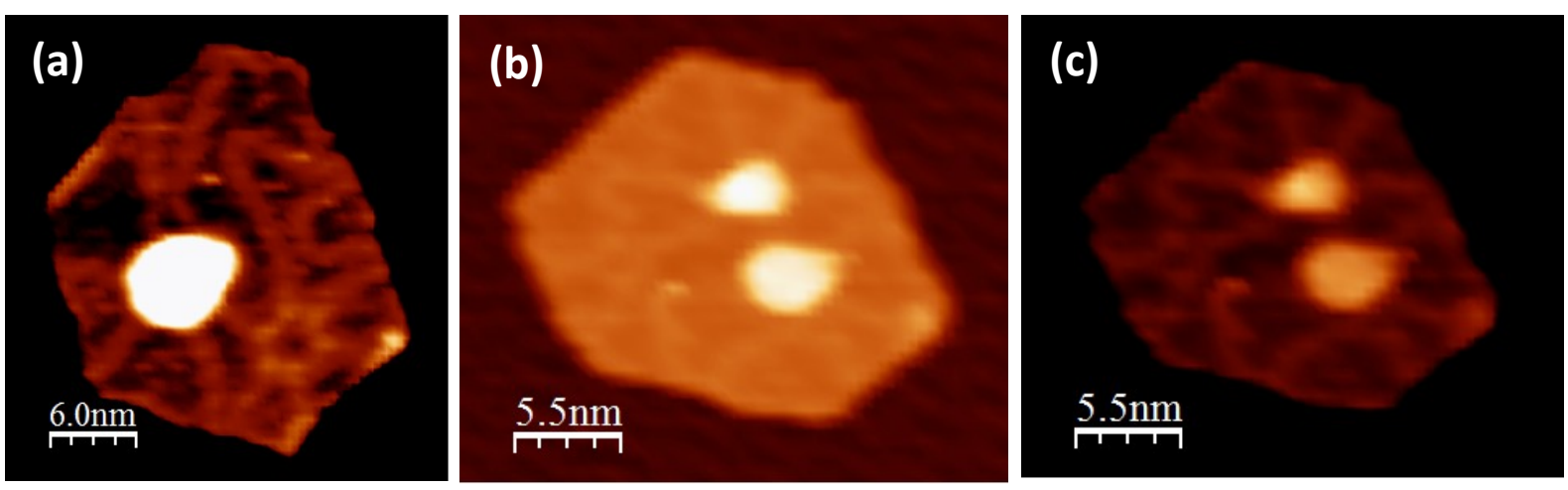

Figure S9. (a) Left Pd island in Figure 2 using a higher contrast to clearly reveal the dislocation lines. (b) and (c) show the same Pd island (different from (a)) with lower and higher contrast. 

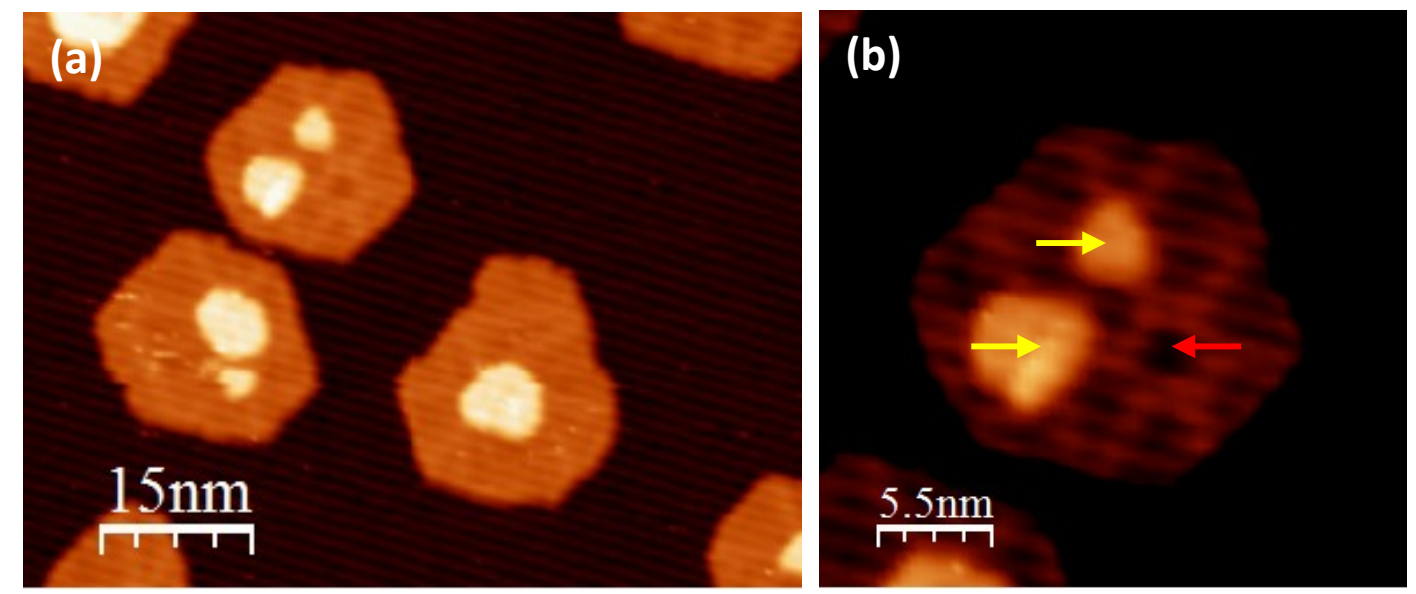

Figure S10. (a) STM topographic images of $0.30 \mathrm{ML}$ of Pd on $\mathrm{Ag}(111)$. Three defects that serve as nucleation sites are marked with arrows in (b). Ag atoms have already nucleated at the sites marked with the yellow arrows but have yet to do so at the red arrow. The striped features are artefacts presumably due to vibrations picked up by the STM.

\section{S6. Line Profiles of Single Pd Atoms in a Ag-capped Pd Island}
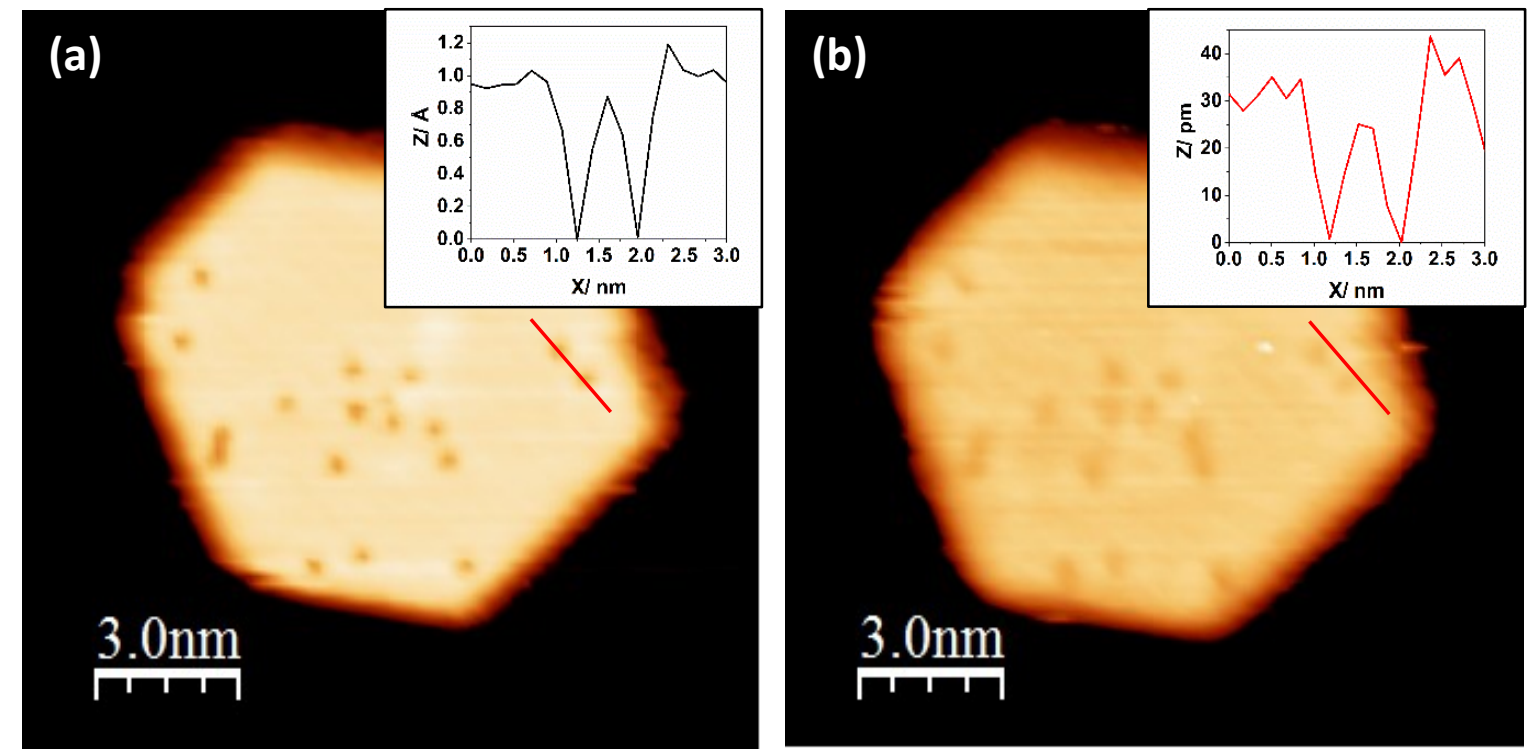

Figure S11. (a) STM topographic image of the island before the tip change. Inset shows the height profile along the red line. Depth of the depressions is $\sim 90 \mathrm{pm}$. (b) STM topographic image after the tip change. Inset shows the height profile along the red line. Depth of the depression is $\sim 32 \mathrm{pm}$. Images were recorded at $0.8 \mathrm{nA}$ and $1.0 \mathrm{~V}$. 